\title{
PROSPECTIVE STUDY OF INTERNAL FIXATION OF DIAPHYSEAL FRACTURES WITH LIMITED CONTACT-DYNAMIC COMPRESSION PLATING
}

\author{
Mohammed Abdul Wahed ${ }^{1}$, P. N. Prasad ${ }^{2}$ \\ ${ }^{1}$ Associate Professor, Department of Orthopaedics, Shadan Medical College, Hyderabad, Telangana State. \\ 2 Professor, Department of Orthopaedics, Shadan Medical College, Hyderabad, Telangana State.
}

\section{ABSTRACT}

\section{OBJECTIVES}

To study the concept of biological plating with limited contact dynamic compression plate. The term L.C.-D.C.P stands for a new concept of plate fixation, which can by giving primary importance to the vascularity of the tissues reduces operative trauma to the bone, preserves blood supply, avoids stress risers produced at implant removal, prevents porosis of the plated bone segment and helps in better callous bridging, resulting in early and better functioning of the limb.

\section{MATERIAL AND METHODS}

During the period of 2 years, 30 cases have been studied for the effect of internal fixation of diaphyseal fractures with L.C.-D.C.P. with the concept of biological internal fixation. Maximum follow-up period was 16 months.

\section{RESULTS}

The results were good with uneventful recovery of 26 cases and with complications in the other one case as follows: Post-operative infection and delayed union. The overall results of encouraging comparative conventional methods of plating justifying the utility of new concept and implant.

\section{KEYWORDS}

Internal Fixation, L.C.-D.C.P., Biological Plating, Blood Supply, Stress Risers, Porosis, Bridging Callous.

HOW TO CITE THIS ARTICLE: Wahed MA, Prasad PN. Prospective study of internal fixation of diaphyseal fractures with limited contact-dynamic compression plating. J. Evolution Med. Dent. Sci. 2016;5(13):583-587, DOI: 10.14260/jemds/2016/133

\section{INTRODUCTION}

Based on the Lambotte's principles AO/ASIF formulated four treatment guidelines for fracture treatment. ${ }^{1}$

1. Anatomical reposition of fracture fragments.

2. Sound internal fixation fulfilling local biomechanical demands.

3. Preservation of blood supply to injured area.

4. Active pain free mobilization of adjacent muscles and joints to prevent fracture disease.

The method of applying these principles have been further refined by better understanding of bone biology giving rise to the concept of biological plating. ${ }^{2}$ The newly designed limited contact dynamic compression plate is technically further development of dynamic compression plate based on the experimental work of Klaue and Perren, 1982.

Emphasis is placed on vascular support of bone and soft tissues in order to maintain good bone structure, to enhance resistance against infection and provide the best conditions for early bone healing. ${ }^{3}$

The first attempts at what is now called as biological plating date back some forty years. ${ }^{4}$ (Boitzy and Weber, pers. Com. 1964).

Financial or Other, Competing Interest: None.

Submission 28-12-2015, Peer Review 24-01-2016,

Acceptance 30-01-2016, Published 15-02-2016.

Corresponding Author:

Dr. Mohammed Abdul Wahed,

12-2-823/A/86, FL. No. 301,

Double Tree Apts. Santosh Nagar Colony,

Mehdipatnam, Hyderabad-500028.

E-mail: wahed35@hotmail.com

DOI: $10.14260 /$ jemds $/ 2016 / 133$
The development of indirect reduction technique (Mast et al. 1987). Wave plate (Brenner and Weber, 1981) and bridging plate (Heitmeyer, et al. 1985) brought about basic change in the approach to fracture treatment.

The newly designed limited contact dynamic compression plate is technically a further development of dynamic compression plate based on the experimental work of Klaue and Perren (1982), who developed its predecessor Dynamic Compression Unit (DCU). ${ }^{5}$

The structure of limited contact dynamic compression plate is designed to achieve compression as well as to preserve vascularity of underlying bone and surrounding soft tissue providing best conditions for bone healing. ${ }^{6}$

\section{SURGICAL AND APPLIED ANATOMY OF DIAPHYSIS. ${ }^{7}$}

A typical long bone consists of three regions diaphysis, metaphysis and epiphysis. Diaphysis is the central portion of long bone consisting of a thick walled tube of compact bone, which thins out at the expanded ends or metaphysis to form a shell around a mass of cancellous bone. Running through the cancellous bone near the junction of the expanded end with the shaft is a line of dense bone called the epiphyseal scar marking the site of original epiphyseal plate of cartilage. The medullary cavity in the centre of the shaft contains yellow marrow. The surface of the shaft and parts of the ends are covered by periosteum consisting of two layers. Outer fibrous layer acting as a limiting membrane and deeper vascular layer containing blood vessels and cells which can when necessary lay down new bone on the surface of the shaft. Toward the end of the bone, the periosteum blends with the fibrous capsule of the joints in which the bone is involved. The end of long bones are covered by articular cartilage. 


\section{BLOOD SUPPLY OF LONG BONES. 8}

The blood supply of the long bones is derived from three principal sources:

1. The main nutrient artery. 2. The anastomosing vessels in the vicinity of the ends of the bone. 3 . Small vessels in the vascular layer of periosteum.

The nutrient artery which is accompanied by a vein enters a nutrient foramina near the middle of the shaft usually at an oblique angle directed away from growing end. Within the medullary cavity divide and the divisions pass towards each end of the bone giving numerous branches, which enter the deep surface of the compact cortical bone. These branches enter the Haversian canal and pass through the bone mainly running longitudinally. They finally reach the surface anastamose with the periosteal vessels.

At each end of the bone, some arteries and numerous veins enter the bone through foramen of various sizes. These arteries are branches of local vessels and also derived from arterial anastomosis around the corresponding joint. They enter the bone on both sides of epiphyseal scar and therefore classified as metaphyseal and diaphyseal scar, although before fusion of epiphysis forming different systems.

The direction of blood flow is said to be largely centrifugal. It is probable that periosteal vessels are important in nutrition of outer layers of bone.

The main supply to the periosteal vascular plexus is by means of vessels from the locally attached muscles, hence large bare areas of bone have a poor blood supply. The distribution of blood vessels often has a bearing on the healing of fractures.

\section{BIOMECHANICAL FEATURES OF THE LIMITED CONTACT DYNAMIC COMPRESSION PLATE. 9}

The limited contact dynamic compression plate is made from a prismatic piece of metal. Plate holes are positioned at equal distances along the plate. Plate holes are symmetrical and provided with two identical self-compressing inclined surfaces at each end. The sides of the plate are slightly inclined to form a trapezoid cross-section interrupted by undercuts, which form areas at these locations. The cross-section has two very steep sides. The clearance for the plate hole and the above mentioned undercuts results in important reduction of the contact surfaces. The inclined undercuts at each end of the plate hole allow for extensive angulation of the screw in the plate hole and simultaneously help to further reduce the contact surface.

The shaft screw is partially threaded. The unthreaded shaft having same diameter as the outer diameter of the thread preventing secondary wedging. On insertion of shaft screw as lag screw the shaft does not engage the near cortex providing lag effect secondary to movement of a screw in the direction other than along its longitudinal axis during tightening.

The shaft portion is 5 times stiffer and 3.4 times stronger in bending than the threaded portion contributing to improvement of axial compression and supplements selfcompressing effect of the plate.

\section{ADVANTAGES OF THE LIMITED CONTACT DYNAMIC COMPRESSION PLATE.10}

Limited contact dynamic compression plate is designed to incorporate certain features keeping in view the concept of biological internal fixation.
1. Structured undersurface of the plate significantly improves the blood supply of plated bone segments, such grooves must be of adequate width and depth.

2. Grooves in the undersurface of the plates allow for a small amount of callus formation at the most critical area with marked increase in fracture healing strength.

3. By providing grooves between the holes, the uniform cross-section of the plate is maintained with the result that holes do not act as stress risers and evenly distributed stiffness of the plate is maintained facilitating uniform contouring of plate and prevention of deformation of plate holes when the plate is exposed to bending load or during the process of contouring.

4. Oblique undercuts near the undersurface at both ends of the plate hole allow 40 degrees tilting each way along the long axis of the plate for the screws. The plate screws, which function as lag screws can then be used to stabilize short oblique fracture surfaces furthermore the undercuts reduce the contact area between plate and the bone.

5. Uniform spacing of the plate holes allow for easy shifting and placement, which contributes greatly to the versatility of the plate, especially in multifragmentary fracture fixation.

6. Principle of spherical gliding of the screw head under surface is implemented at both ends of each plate hole, which allows more versatility in handling complex situations, i.e. segmental fractures, interfragmentary compression in either direction.

7. The trapezoid cross-section with smaller surface contact results in broader and lower side lamella formation, which are stronger and less likely to get damaged at plate extraction, thereby prevent forming stress risers and possible refracture after implant extraction.

8. Elongated and undercut plate holes together with a screw that has shaft corresponding to outer diameter of thread to prevent secondary wedging and more stiffness of shaft portion of screw contributes in improvement of axial compression and supplements the selfcompressing effect of the plate.

9. Undercuts preserve vascularity of plated bone segment, thereby preventing sequestration and improve bone healing with increased resistance to infection.

10. Stress shielding is minimal.

\section{MATERIAL AND METHODS}

During the period of two years, thirty cases of diaphyseal fractures are treated by open reduction and internal fixation with limited contact dynamic compression plate and shaft screws in unit-I of Department of Orthopedics and Traumatology, Osmania General Hospital, Hyderabad.

- The patients were selected randomly from the admitted cases in the unit in regard to age, sex, mode of injury, site and configuration of fracture.

- Preoperative evaluation was done in all cases regarding fitness for anaesthesia.

- All the patients were operated after stabilization of their general condition during the first week after admission or later.

- Either spinal, brachial or general anaesthesia was given according to the preference of the anaesthetist. 
- Standard positioning of the patient was done as per the requirement of the part operated. Tourniquet was employed whenever feasible.

- Standard surgical approaches were utilized for exposure of fracture.

- Cancellous bone grafting was done in case of non-union.

- Vacuum suction drain employed in all cases and removed on 2 nd postoperative day.

- Intraoperative and postoperative third generation cephalosporins given in all cases and antibiotics and analgesics continued for 10 days postoperatively.

- Primary dressing done on 2 nd postoperative day followed by suture removal on 10th postoperative day.

- External support given in cases of non-union and comminution.

- Non-weightbearing active mobilization of the part done immediately postoperatively.

- Followup was done at intervals of one month and fracture union assessed clinically and radiologically and functional recovery assessed.

- Stainless steel limited contact dynamic compression plates of AO design with cortico-cancellous (shaft)/cortical screws are utilized for fixation of fractures.

- The procedure advocated by AO/ASIF group for fixation of fracture with LC-DCP was employed in all cases.

- Results are graded according to the method of Lewis. D. Anderson.

\section{ANALYSIS OF CASES}

Thirty cases of diaphyseal fractures were treated by internal fixation with limited contact dynamic compression plating during a period of two years in the Department of Orthopedic Surgery and Traumatology Unit-1 of Osmania General Hospital, Hyderabad formed the basis of this study.

\begin{tabular}{|c|c|c|}
\hline Age group in years & No. of Cases & Percentage \\
\hline $0-20$ & 9 & 29.99 \\
\hline $20-40$ & 17 & 56.61 \\
\hline $40-60$ & 2 & 6.66 \\
\hline 60 and above & 2 & 6.66 \\
\hline \multicolumn{2}{|c|}{ TABLE 1: AGE INCIDENCE } \\
\hline
\end{tabular}

\begin{tabular}{|c|c|c|}
\hline Sex & No. of Cases & Percentage \\
\hline Male & 23 & 76.59 \\
\hline Female & 7 & 23.31 \\
\hline \multicolumn{3}{|c|}{ TABLE 2: SEX INCIDENCE } \\
\hline
\end{tabular}

\begin{tabular}{|c|c|c|}
\hline Mode of Injury & $\begin{array}{c}\text { No. of } \\
\text { Cases }\end{array}$ & Percentage \\
\hline Moving vehicle accident & 18 & 60 \\
\hline Fall from height & 3 & 10 \\
\hline Assault & 3 & 10 \\
\hline Accidental fall & 2 & 6.6 \\
\hline $\begin{array}{c}\text { Direct injury by heavy } \\
\text { objects }\end{array}$ & 3 & 10 \\
\hline \multicolumn{2}{|c|}{ Osteotomy } & 3.33 \\
\hline \multicolumn{2}{|c|}{ TABLE 3: MECHANISM OF INJURY } \\
\hline
\end{tabular}

\begin{tabular}{|c|c|c|}
\hline Bones Involved & No. of Cases & Percentage \\
\hline Upper limb & 24 & 80 \\
\hline Humerus & 13 & 43.33 \\
\hline Forearm & 11 & 36.66 \\
\hline Lower limb & 6 & 20 \\
\hline Femur & 3 & 10 \\
\hline Tibia & 3 & 10 \\
\hline \multicolumn{2}{|c|}{ TABLE 4: SITE OF FRACTURE } \\
\hline
\end{tabular}

\begin{tabular}{|c|c|c|}
\hline Side & No. of Cases & Percentage \\
\hline Right & 13 & 43.33 \\
\hline Left & 15 & 50 \\
\hline Multiple injury & 2 & 6.66 \\
\hline \multicolumn{2}{|c|}{ TABLE 5: SIDE OF FRACTURE } \\
\hline
\end{tabular}

\begin{tabular}{|c|c|c|}
\hline Type & No. of Cases & Percentage \\
\hline Transverse & 12 & 39.99 \\
\hline Oblique & 4 & 13.33 \\
\hline Spiral & 3 & 10 \\
\hline Comminuted & 11 & 36.66 \\
\hline \multicolumn{2}{|c|}{ TABLE 6: FRACTURE CONFIGURATION } \\
\hline
\end{tabular}

\begin{tabular}{|c|c|c|}
\hline No. of Days & No. of Cases & Percentage \\
\hline 0-15 days & 10 & 33.33 \\
\hline 15-30 days & 14 & 46.66 \\
\hline 30 days and above & 6 & 19.99 \\
\hline \multicolumn{2}{|c|}{ TABLE 7: HOSPITAL STAY } \\
\hline
\end{tabular}

Majority of patients were kept in-patient for socioeconomic reasons (Outstationed and poor) rather than technical reasons.

\section{RESULTS}

\section{FRACTURE UNION}

Fracture union was observed in all the thirty cases, which are studied in expected time.

\begin{tabular}{|c|c|c|}
\hline Duration of Union & No. of Cases & Percentage \\
\hline Up to 8 weeks & 4 & 13.34 \\
\hline 8-12 weeks & 21 & 70 \\
\hline 12-16 weeks & 4 & 13.34 \\
\hline Above 16 weeks & 1 & 3.32 \\
\hline
\end{tabular}

\section{MOVEMENTS}

In the thirty cases, regain of complete range of movement is seen in 22 cases. Terminal restriction of 5 to 10 degrees seen in 5 cases. Terminal restriction of 10 to 12 degrees in 3 cases in 24 weeks follow-up.

\section{FUNCTIONAL OUTCOME}

All patients regained function of the $\operatorname{limb}$ without any postoperative complications.

Grading of results: We followed the method of Lewis D. Anderson in grading results.

Excellent: Union with less than $10^{\circ}$ of loss of movement in adjacent joints.

Satisfactory: Union with less than $20^{\circ}$ of loss of movement in adjacent joints.

Unsatisfactory: Union with more than $30^{\circ}$ loss of movement in adjacent joints.

Poor: Nonunion and those with complications. 


\section{GRADING OF RESULTS}

\begin{tabular}{|c|c|c|}
\hline Grading & No. of Cases & Percentage \\
\hline Excellent & 27 & 90 \\
\hline Satisfactory & 3 & 10 \\
\hline Unsatisfactory & - & - \\
\hline Poor & - & - \\
\hline
\end{tabular}

The table showing various series of plating in Osmania General Hospital, Hyderabad.

\begin{tabular}{|c|c|c|c|c|}
\hline Result & LC-DCP & DCP & $\begin{array}{c}\text { Eggers } \\
\text { plating }\end{array}$ & $\begin{array}{c}\text { Semi- } \\
\text { tubular } \\
\text { plating }\end{array}$ \\
\hline Excellent & $\begin{array}{c}27 \\
(90 \%)\end{array}$ & $\begin{array}{c}28 \\
(89.50 \%)\end{array}$ & $\begin{array}{c}21 \\
(53.80 \%)\end{array}$ & $\begin{array}{c}18 \\
(60 \%)\end{array}$ \\
\hline Good & $3(10 \%)$ & $4(12.50 \%)$ & $13(23.3 \%)$ & $\begin{array}{c}8 \\
(26.7 \%)\end{array}$ \\
\hline Fair & - & - & $3(10.2 \%)$ & $2(7 \%)$ \\
\hline Poor & - & - & $2(5 \%)$ & $2(7 \%)$ \\
\hline
\end{tabular}

The results of limited contact Dynamic Compression Plating for diaphyseal fractures is found to be superior to various techniques of internal fixation in our study. In hundred percent of cases union was certainty and in $90 \%$ of cases the functional recovery is total and in $10 \%$ near normal.

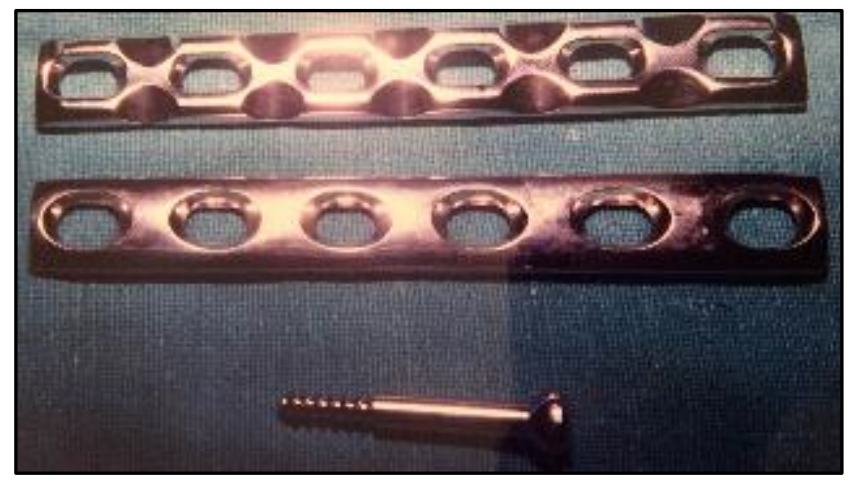

Fig. 1

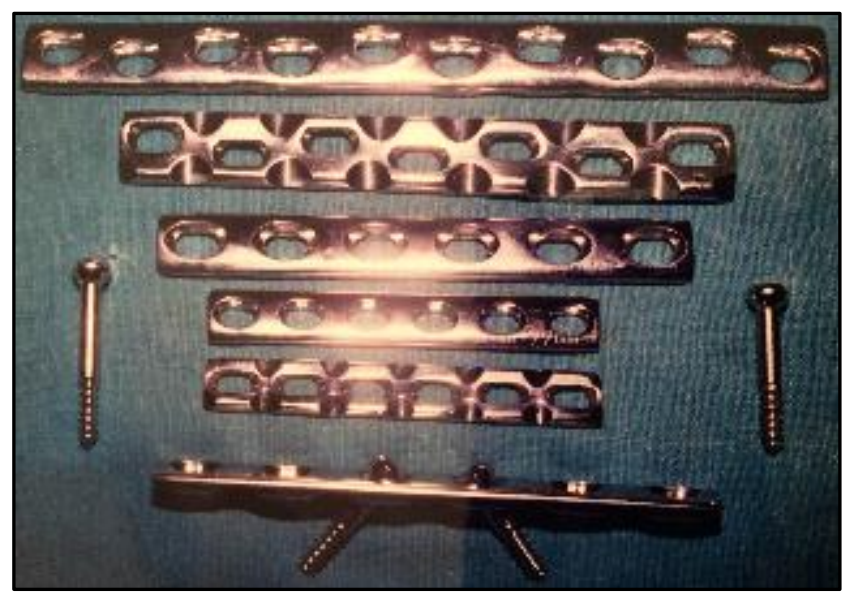

Fig. 2

\section{DISCUSSION}

Diaphyseal fractures of long bones are the commonest fractures encountered in Orthopaedic emergency. They are the outcome of high energy trauma in vehicular domestic and industrial accidents involving mostly active, productive younger age group.

In many of these cases bone instability and unacceptable shortening, displacement and deformity result which is not compatible with return to normal functioning and early sound fracture union unless corrected.

Fractures treated conservatively require long period of immobilization and is likely to produce fracture disease manifesting as joint stiffness, poor muscle tone and strength. Poor soft tissue flexibility, altered or impaired neurocirculatory status and osteoporosis.

Many fractures are not amenable to conservative management due to difficulty in achieving anatomical reduction and maintenance of position, because of the strong forces acting in the form of muscles and gravity. Maintenance of immobilization is difficult in cases of multiple injuries.

Early ambulation of the patient is desirable in elderly age group to prevent complications inherent in immobilization of elderly patients.

By achieving maximum functional recovery in minimal duration to make the patient job-worthy, financial burden on the patient as well as the hospital resources can be reduced and make it possible for the patient to attend to his social obligations.

With limited contact dynamic compression plating, sound internal fixation excludes the necessity for any external support or immobilization. Mobilization of the limb can be started in immediate postoperative period and rehabilitation is shortened.

With preservation of vascularity at the site of injury, early sound fracture union and maximal functional recovery can be achieved minimizing the complications of fracture management.

The results of management of diaphyseal fractures with limited contact dynamic compression plating was found to be excellent in our study and is superior to other plating techniques.

\section{CONCLUSION}

The following observations are made during the study of management of diaphyseal fractures by limited contact dynamic compression plating.

1. It offers sound fixation of diaphyseal fractures.

2. All the fractures treated in the series have united in acceptable duration clinically and radiologically.

3. Full functional recovery was found early and patients could return to their earlier jobs without any disability.

4. Surgical trauma was minimal compared to other methods.

5. There was no need of external support.

6. Hospital stay was reduced, reducing the cost of therapy and optimal use of personnel.

7. Early achievement of job-worthiness.

8. Complications, implant failures, non-unions and infections were not encountered.

With this observation, we are of the opinion that LC-DC Plating in diaphyseal fracture management is superior to other presently available modalities of fracture management if properly planned and exhibited. 


\section{REFERENCES}

1. Crenshaw AH. Campbell's operative orthopaedics, $8^{\text {th }}$ Edition, 1992, Missouri, USA, Mosby Yearbook Ch 22, page 737-8.

2. Perren SM. The concept of biological plating using the LCDCP. Scientific background, design and application. Injury 22 Suppl 1:1-41, 1991.

3. Gautier E, Perren SM. Limited contact dynamic compression plate: Biomechanical research as basis to new plate design. Ortho 21(1):11-23, $1992 \mathrm{Feb}$.

4. Gaglay GW, Spokane MD, et al. Compression bone plating, historical considerations. JBJS 58A, 625-631, 1977.

5. Haas N, Krettek C. New trends in management of shaft fractures. Langenbecks Archives for Chirurgie, Suppl Kongressbd 478-86, 1991.
6. Anderson LD. Compression plate fixation and the effect of different types of internal fixation on fracture healing. JBJS 47A, 191-208, (1965).

7. Romanes GJ. Cunningham's Manual of Practical Anatomy: Vol. 1, 15th Edition, 1987, Hongkong, Page No. 246-255.

8. Roger Warwick, Peter L Williams. Gray's Anatomy, 35th Edition 1973, Longman, Great Britain, Ch. No. 3, Page No. 221.

9. Willinger H Asif: Instrumentation, 1981.

10. Perren SM, Klaue K, Poochlev O, et al. The limited contact dynamic compression plate: archives of orthopaedics and trauma-surgery 109(6):304-10, 1990. 